\title{
Synaptic Modulation by Neurotrophic Factors: Differential and Synergistic Effects of Brain-Derived Neurotrophic Factor and Ciliary Neurotrophic Factor
}

\author{
Ron Stoop and Mu-ming Poo \\ Department of Biological Sciences, Columbia University, New York, New York 10027
}

\begin{abstract}
Extracellular application of brain-derived neurotrophic factor (BDNF) and ciliary neurotrophic factor (CNTF) to developing neuromuscular junctions in Xenopus nerve-muscle cultures resulted in an increase in the frequency of spontaneous synaptic currents (SSCs) and in the amplitude of nerve-evoked synaptic currents. Analyses of the amplitude and time course of the SSCs suggest that these effects are attributable to elevation of presynaptic transmitter release. The actions of these two factors on the transmitter secretion process, however, are distinctly different. Fura- $2 \mathrm{Ca}^{2+}$ imaging showed that an increase in presynaptic cytosolic $\mathrm{Ca}^{2+}\left(\left[\mathrm{Ca}^{2+}\right]_{\mathrm{i}}\right)$ accompanied the synaptic potentiation by BDNF, whereas no change in $\left[\mathrm{Ca}^{2+}\right]_{i}$ was observed during synaptic potentiation by CNTF. Removing external $\mathrm{Ca}^{2+}$ also abolished the potentiating effect of BDNF but did not influence the CNTF effect. Moreover, the two factors
\end{abstract}

exerted different effects on the short-term synaptic plasticity. Paired-pulse facilitation normally found at these synapses was reduced by BDNF but unaffected by CNTF; CNTF, but not BDNF, reduced the extent of synaptic depression during highfrequency tetanic stimulation. Finally, the potentiation effect of BDNF and CNTF on spontaneous transmitter release was additive when both factors were applied together to the synapse at saturating concentrations $(100 \mathrm{ng} / \mathrm{ml})$ and was highly synergistic when low doses (1 and $10 \mathrm{ng} / \mathrm{ml}$ ) of both factors were used. These results suggest that because of their differential effects on the secretory machinery, BDNF and CNTF may act cooperatively in modulating the development and functioning of synapses.

Key words: BDNF; CNTF; neurotransmitter release; Fura-2 imaging; paired-pulse facilitation; synaptic plasticity; synergism
Neurotrophic factors are known to play important roles in the survival and differentiation of many types of neurons during development. Brain-derived neurotrophic factor (BDNF), neurotrophin-3 (NT-3), and NT-4/5, members of the neurotrophin family, promote motor neuron survival in vitro and rescue motor neurons from naturally occurring or axotomy-induced cell death (Sendtner et al., 1992; Yan et al., 1992; Henderson et al., 1993; Koliatsos et al., 1993). Mice carrying a null mutation in the BDNF gene show deficits of sensory neurons, although motor neuron survival was not affected (Conover et al., 1995; Liu et al., 1995). Ciliary ncurotrophic factor (CNTF), a member of the cytokine family of neurotrophic factors, also promotes survival of embryonic motor neurons in vitro (Arakawa et al., 1990) and in vivo (Oppenheim et al., 1991; Forger et al., 1993). A null mutation in the CNTF gene results in progressive motor neuron atrophy and postnatal neuron loss (Masu et al., 1993).

Most observations on the survival and differentiation effects of neurotrophic factors relate to long-term trophic functions of these factors. On the other hand, the activities of downstream kinases and effector proteins are known to be induced soon after binding of the factors to the neuron (for reviews, see Heumann, 1994; Greene and Kaplan, 1995). These cytosolic activities may lead to immediate alterations of neuronal functions. For example,

\footnotetext{
Received Nov. 13, 1995; revised Feb. 26, 1996; accepted Feb. 28, 1996.

This work was supported by a grant from the National Science Foundation (IBN-92-22106). We thank Regeneron Inc. for kindly providing recombinant RDNF and CNTF.

Correspondence should be addressed to Dr. Mu-ming Poo at his present address: Department of Biology, University of California at San Diego, La Jolla, CA 920930357.

Copyright $(c) 1996$ Society for Neuroscience $0270-6474 / 96 / 163256-09 \$ 05.00 / 0$
}

marked morphological changes of nerve growth cones were induced within minutes after exposure of PC12 cells to nerve growth factor (Connolly et al., 1985, 1987). In Xenopus nerve-muscle cultures, Lohof et al. (1993) showed that within 10-20 min after addition of the neurotrophins BDNF and NT-3, both spontaneous and evoked transmitter release at developing neuromuscular synapses were potentiated. Similar potentiation effects were also found after application of CNTF to these developing synapses (Stoop and Poo, 1995). Because these two factors are known to exert their effects via different receptors and intracellular signal transduction cascades, it is of interest to examine further whether synaptic potentiation by BDNF and CNTF was attributable to modulation of the same cellular loci of the secretory pathway within the nerve terminal. In the present study, the synaptic effects of BDNF and CNTF under various conditions were compared further to reveal differences in their presynaptic actions. The potential additive or synergistic actions of these two factors at the synapse were also examined.

\section{MATERIALS AND METHODS}

Culture preparations and chemicals. Xenopus cultures were prepared as described previously (Spitzer and Lamborghini, 1976; Tabti and Poo, 1991). Briefly, neural tubes and the associated myotomal tissue of 1-d-old Xenopus embryos (stage 20-22 according to Nieuwkoop and Faber, 1967) were dissociated in $\mathrm{Ca}^{2+} / \mathrm{Mg}^{2+}$-free saline supplemented with EDTA $(115 \mathrm{~mm} \mathrm{NaCl}, 2.6 \mathrm{~mm} \mathrm{KCl}, 0.5 \mathrm{~mm}$ EDTA, $10 \mathrm{~mm}$ HEPES, pH 7.60) for 15-20 min. The cells were plated on glass coverslips and were used for experiments after $24 \mathrm{hr}$ incubation at room temperature. The culture medium consisted of (vol/vol) 50\% Leibovitz L-15 medium (Sigma, St. Louis, MO), $1 \%$ fetal calf serum (Gibco, Gaithersburg, MD), and 49\% Ringer's solution (115 mM NaCl, $2 \mathrm{mM} \mathrm{CaCl}_{2}, 2.5 \mathrm{~mm} \mathrm{KCl}, 10 \mathrm{~mm}$ HEPES, pH 7.6). For experiments performed under zero external $\mathrm{Ca}^{2+}$ conditions, the culture medium was replaced with a solution containing 

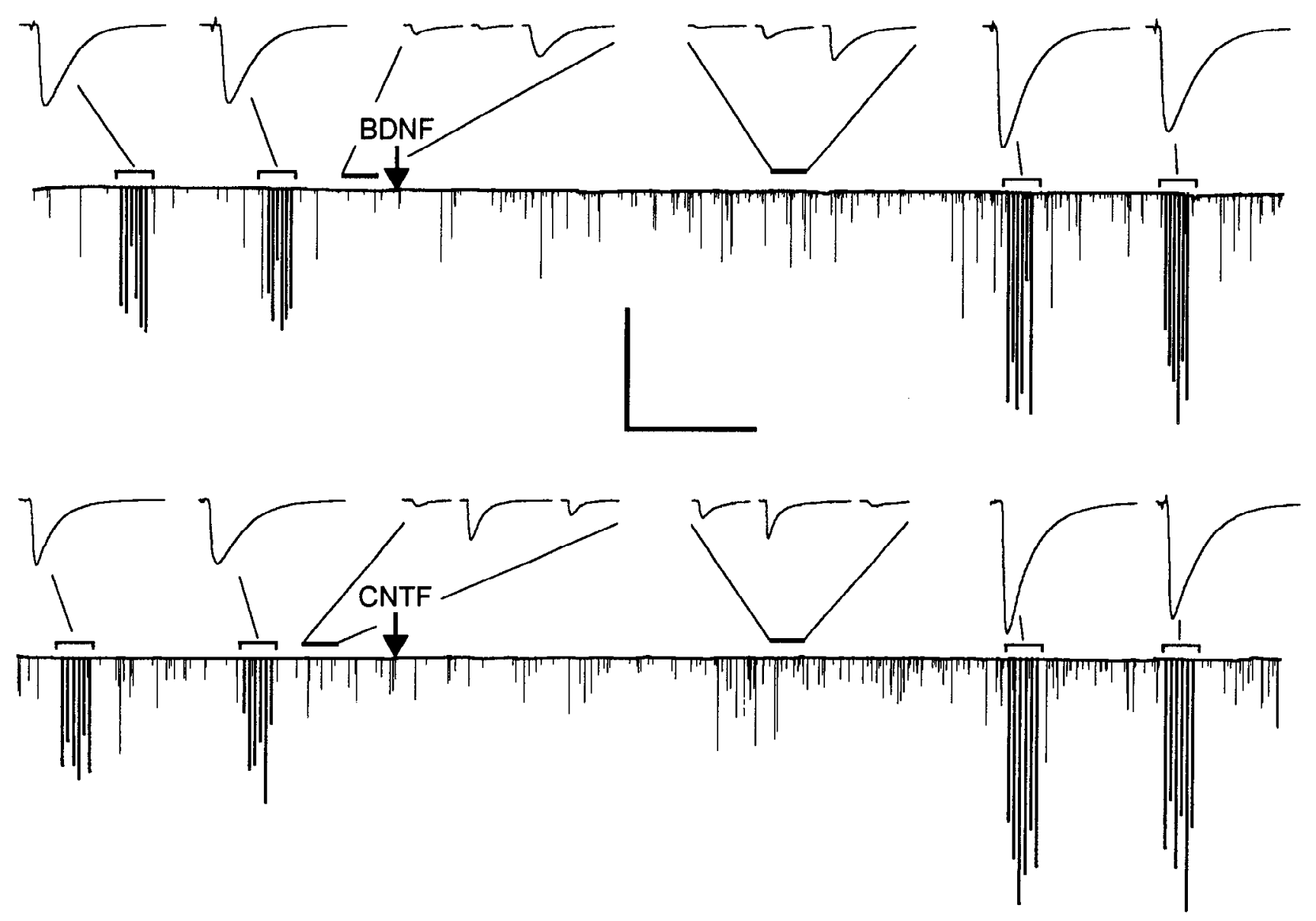

Figure 1. Potentiation of SSCs and ESCs by brain-derived neurotrophic factor (BDNF) and ciliary neurotrophic factor $(C N T F)$ at developing Xenopus neuromuscular synapses. The continuous traces depict membrane currents recorded from innervated myocytes under voltage-clamp $\left(V_{\mathrm{h}}=-70 \mathrm{mV}\right)$ in a 1-d-old culture. Downward events are inward currents. SSCs occurred at random and ESCs were elicited at a frequency of $0.05 \mathrm{~Hz}$ at the times marked by the brackets. The arrow marks the time of addition of either BDNF or CNTF to the culture medium (final concentration $100 \mathrm{ng} / \mathrm{ml}$ ). Insets above depict computer-averaged ESCs and samples of SSCs at higher time resolution for the recording periods pointed to by the lines. Calibration: slow traces, 2 nA, $5 \mathrm{~min}$; fast traces, $1 \mathrm{nA}, 20 \mathrm{mscc}$.

$115 \mathrm{~mm} \mathrm{NaCl}, 2 \mathrm{~mm} \mathrm{MgCl}$, $2.5 \mathrm{~mm} \mathrm{KCl}, 10 \mathrm{~mm}$ HEPES, $3 \mathrm{~mm}$ EGTA, and $0.1 \%$ bovine serum albumin (BSA), $\mathrm{pH}$ 7.3. Escherichia coli-derived rat recombinant CNTF and BDNF were obtained from Regeneron (Tarrytown, NY) and aliquoted and stored at a concentration of $0.78 \mathrm{mg} / \mathrm{ml}$ in PBS at $-70^{\circ} \mathrm{C}$ before use. The tetra(acetoxymethyl)-ester form of bis-(oaminophenoxy)-ethane- $N, N, N^{\prime}, N^{\prime}$-tetra-acetic acid (BAPTA-AM) was obtained from Calbiochem (San Diego, CA).

Electrophysiology. Whole-cell patch rccordings (Hamill and Sackmann, 1981) were made in culture medium after $1 \mathrm{~d}$ of incubation at room temperature $\left(20-22^{\circ} \mathrm{C}\right)$. The solution inside the whole-cell recording pipette contained $150 \mathrm{mM} \mathrm{KCl}, 1 \mathrm{mM} \mathrm{NaCl}, 1 \mathrm{mM} \mathrm{MgCl}_{2}$, and $10 \mathrm{mM}$ HEPES, $\mathrm{pH}$ 7.2. The membrane current in all recordings was monitored by a patch-clamp amplifier (EPC-7, List, Great Neck, NY). To monitor long-term ( $>1 \mathrm{hr}$ ) changes in synaptic currents at the same synapse, the whole-cell recording pipette was removed, and repeated recording from the postsynaptic myocyte was carried out later with a different pipette to avoid excessive "washout" of cytosolic components. Data were stored on a videotape recorder for later playback onto a storage oscilloscopc (5113, Tektronix, Beaverton, OR) and a chart recorder (EasyGraf Recorder TA240, Gould, East Rutherford, NJ) and for analysis by the SCAN program (kindly provided by Dr. J. Dempster, Strathclyde University, Glasgow, UK). Unless indicated otherwise, BDNF and CNTF were added to the culture medium, and the recording was made in the presence of the factor throughout the entire course of the experiment. Both spherical and flat myocytes were used for these experiments, because there is no apparent difference in the physiological properties of synapses on thesc two types of cells (Evers et al., 1989).

Fura-2 $\left[\mathrm{Ca}^{2+}\right]_{i}$ imaging. Fura-2 was loaded into the presynaptic neuron in 1-d-old Xenopus nerve-muscle cultures using the whole-cell patch- recording pipette. Fura-2 (Molecular Probes, Eugene, OR) was dissolved in intracellular pipette solution containing $150 \mathrm{~mm}$ potassium gluconate,

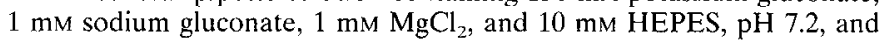
whole-cell patch recording was achieved at the soma of the neuron for a brief period $(2 \mathrm{sec})$ before the pipette was detached. This allowed enough Fura-2 to diffuse into the neuron and attained a fluorescence level (at 380 $\mathrm{nm}$ ) comparable to that observed after 30 min incubation with $3-6 \mu \mathrm{M}$ Fura-2AM (Zheng ct al., 1994). The cultures were then mounted on the stage of an inverted microscope (DIAPHOT, Nikon) equipped with a cooled charge-coupled device (CCD)-based imaging system (CH220 CCD camera, Photometrics, Tucson, AZ). A Nikon $40 \times / 1.3$ numerical aperture Fluor DL objective lens was used throughout the experiments. Fura-2 was excited at 340 and $380 \mathrm{~nm}$ wavelengths alternately through a computer-controlled shutter and filter wheel. The exposure time at each wavelength was $100 \mathrm{msec}$. Paired digital images at 340 and $380 \mathrm{~nm}$ excitation were collected with background subtracted. The cytosolic-free $\mathrm{Ca}^{2+}$ concentration was detcrmincd from the ratio (F340/F380) calculated from the pairs using the ratio method (Grynkiewicz et al., 1985, Tsien and Poenie, 1986). Calibration of $R_{\min }$ (the limiting value that the ratio can have at zero $\left[\mathrm{Ca}^{21}\right]$ ) and $R_{\max }$ (the limiting value that the ratio can have at saturating $\left[\mathrm{Ca}^{2+}\right]$ ) was carried out using standard $\mathrm{Ca}^{2+}$ buffers with 0 and $39.8 \mu \mathrm{M}$ free $\left[\mathrm{Ca}^{2+}\right]$ (Molecular Probes).

\section{RESULTS}

\section{Synaptic potentiation by BDNF and CNTF}

The efficacy of synaptic transmission at developing neuromuscular junctions in Xenopus nerve-muscle cultures was measured by 

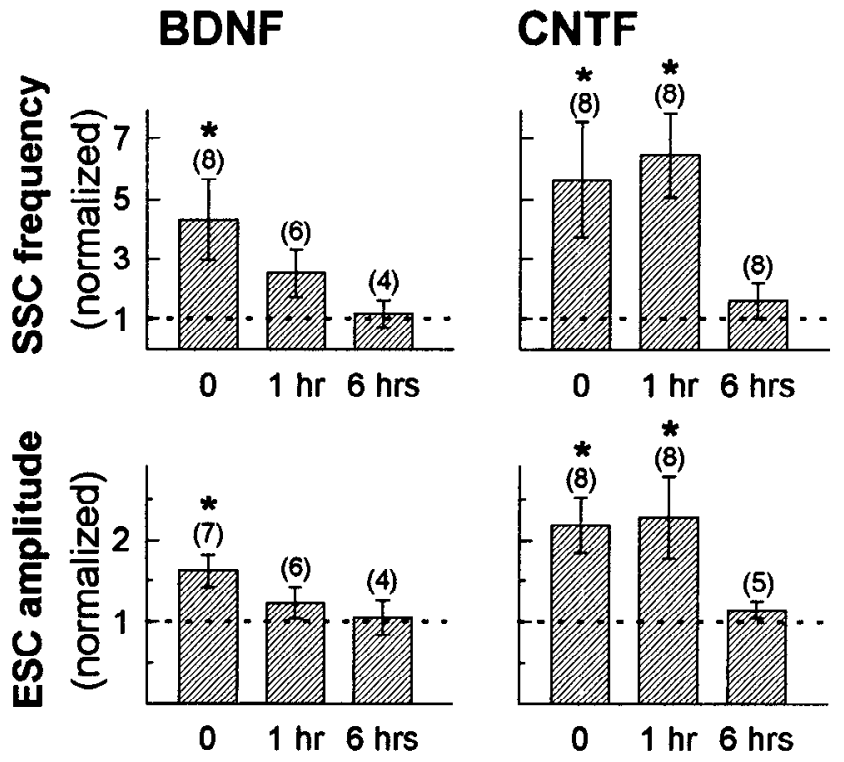

\section{Time after removal}

Figure 2. Time course of reversal of BDNF and CNTF effects. Mean SSC frequency and ESC amplitude were determined immediately $(0), 1 \mathrm{hr}(1$ $h r$ ), and $6 \mathrm{hr}(6 \mathrm{hr})$ after a 30 min treatment with CNTF or BDNF (both at $100 \mathrm{ng} / \mathrm{ml}$ ). The cells were washed thoroughly and incubated with fresh culture medium at the end of the 30 min treatment. The SSC frequency and mean ESC amplitude were normalized for each synapse to the mean values before treatment with the factor. All data are represented as mean \pm SEM; values marked with * are significantly different from the control values at the untreated synapse $(p<0.05, t$ test $)$.

whole-cell recording of spontaneous synaptic currents (SSCs) and impulsc-cvokcd synaptic currents (ESCs) from innervated muscle cells. In agreement with previous reports (Lohof et al., 1993; Stoop and Poo, 1995), we observed an increase in the frequency of the SSCs within 5-10 min after application of either BDNF or CNTF (final concentration, $100 \mathrm{ng} / \mathrm{ml}$ ) to the culture medium. The increase in SSC frequency was accompanied by an increase in the amplitude of the ESCs for both BDNF and CNTF (Fig. 1). The rate of recovery from the potentiated levels after removal of BDNF and CNTF was examined further. As shown in Figure 2, 1 $\mathrm{hr}$ after removal of the factor the potentiation by BDNF of both the SSC frequency and the ESC amplitude had essentially disappeared, whereas the potentiation induced by CNTF remained unchanged. Six hours after removal of the factor, potentiation by both BDNF and CNTF reversed completely to the initial control levels before application of the factors.

Synaptic currents may be enhanced by an increased presynaptic release of transmitter or by an increased postsynaptic sensitivity to the transmitter. An increased postsynaptic acetylcholine (ACh) sensitivity could explain the increase in ESC amplitude as well as an increase in the SSC frequency, because previously undetectable small ACh quanta may emerge after exposure to the factor. As shown in Figure 3, we found no detectable change in the mean, the range, and the distribution of the SSC amplitude, suggesting that it is unlikely that ACh sensitivity had increased by the factor. The absence of any change in the rise time and the decay time of the SSCs after significant elevation of SSC frequency had occurred suggests that thesc factors did not affect the properties of postsynaptic ACh channels (Fig. 3). Thus the primary action of $\mathrm{BDNF}$ and CNTF at these synapses seems to be a presynaptic modulation of transmitter secretion mechanisms.

\section{Effects of BDNF and CNTF on $\left[\mathrm{Ca}^{2+}\right]_{\mathrm{i}}$}

The mechanism by which BDNF and CNTF potentiate presynaptic transmitter secretion was examined further. It has been shown that a rapid increase in $\left[\mathrm{Ca}^{2+}\right]_{i}$ occurs after administration of BDNF to cultured hippocampal neurons (Berninger ct al., 1993). Such elevation of $\left[\mathrm{Ca}^{2+}\right]_{\mathrm{i}}$ may explain a higher frequency of spontaneous transmitter secretion observed after BDNF and CNTF. We thus examined the level of $\left[\mathrm{Ca}^{2+}\right]_{\mathrm{i}}$ in the presynaptic neurons of Xenopus neuromuscular synapses, using the $\mathrm{Ca}^{2+}$. sensitive fluorescence dye Fura-2, before and during a period of 30 min after BDNF or CNTF administration. To measure the level of $\left[\mathrm{Ca}^{2+}\right]_{i}$ in the presynaptic nerve terminal, free from interference of fluorescence from the postsynaptic cell, the presynaptic neuron was loaded with Fura-2 through a whole-cell recording pipette at the soma. Synaptic currents were monitored by another whole-cell recording pipette at the postsynaptic myocyte before and after Fura-2 loading to observe the effect of dye-loading on the level of spontaneous transmitter secretion. To

BDNF

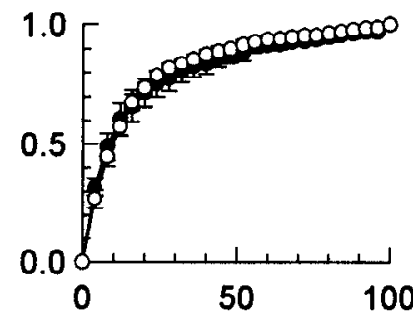

Amplitude (normalized)
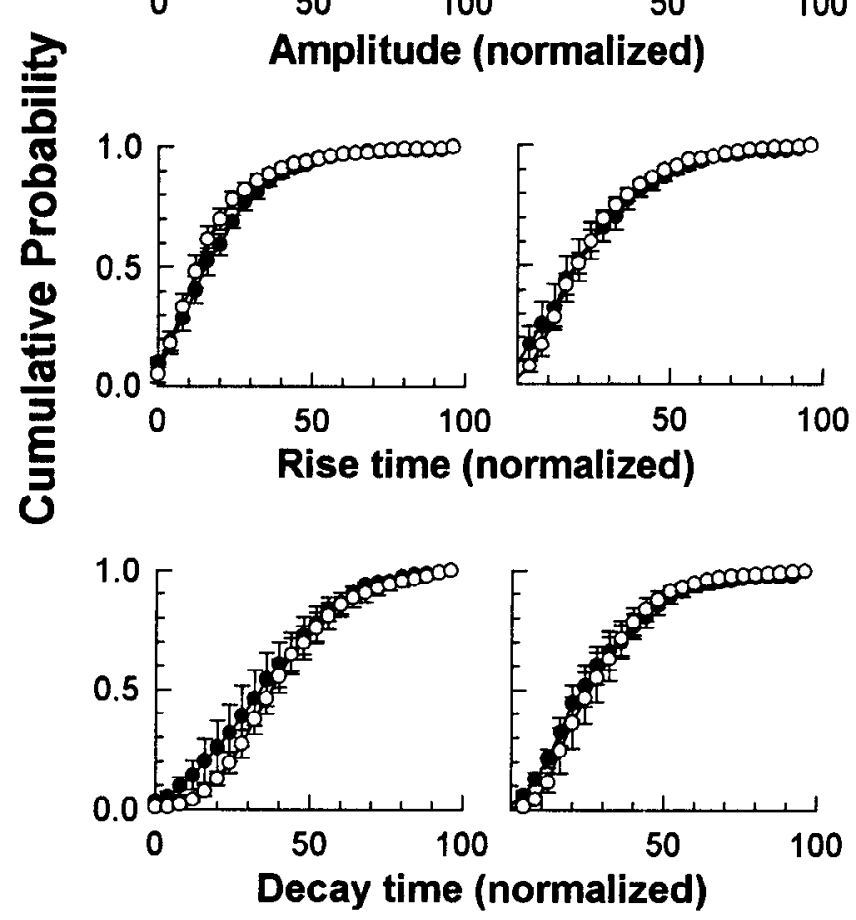

Figure 3. Absence of any change in the properties of SSCs. The amplitude, rise time, and decay time distributions of SSCs before and after BDNF and CNTF treatment were compared. Values observed for each synapse were normalized to the maximal value that included $95 \%$ of all events. The cumulative probability refers to the fraction of total events with values smaller than a given value before (closed circles) and after (open circles) addition of the factor. Synapses in the left column were treated with BDNF $(n=9)$, and synapses in the right column were treated with CNTF $(n=8)$. Data points represent mean \pm SEM. 

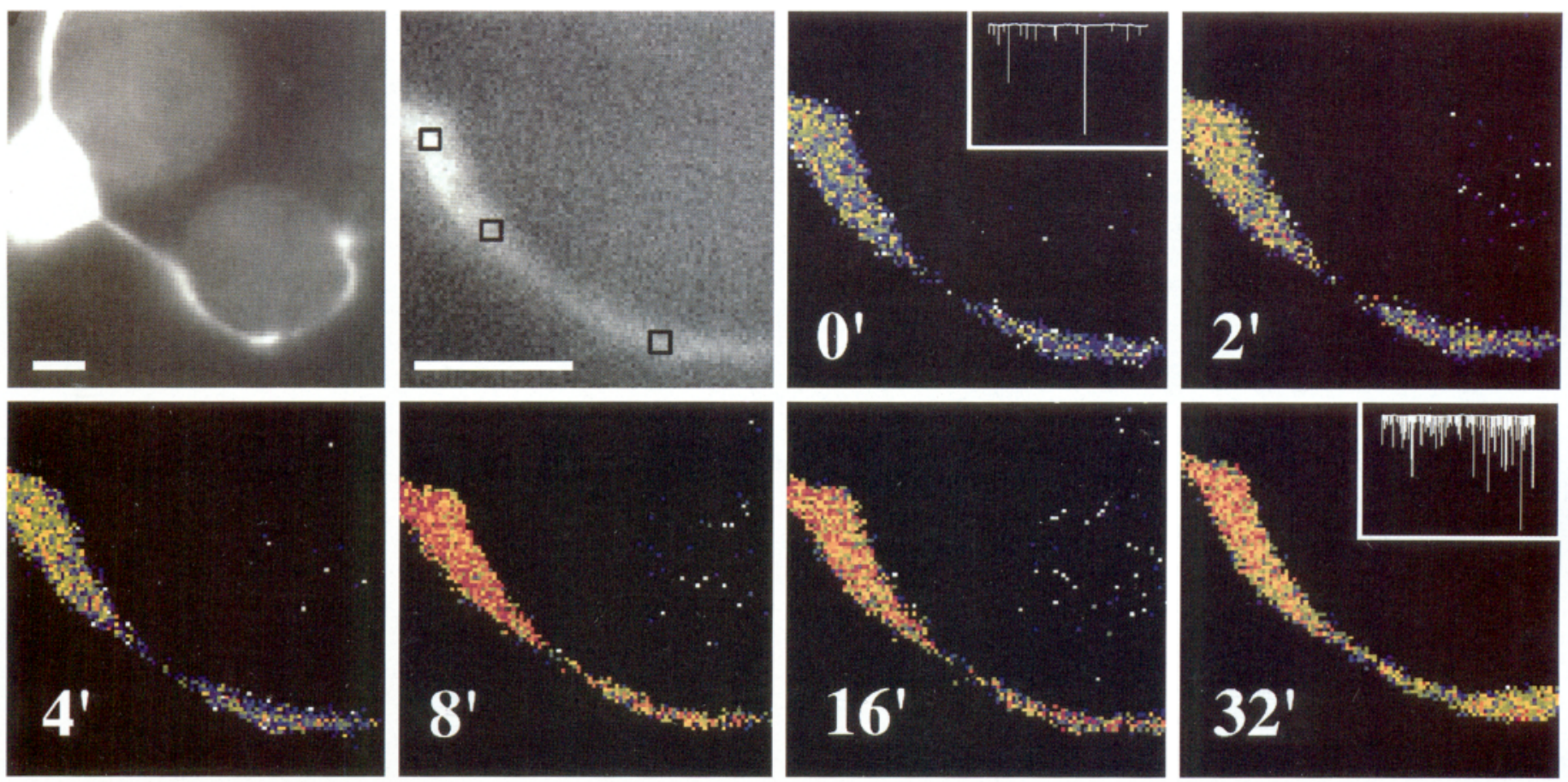

\begin{tabular}{|llllll}
\hline 0.1 & 0.2 & 0.3 & 0.4 & 0.5 & $\mu \mathrm{M} \mathrm{Ca}^{2+}$ \\
\hline
\end{tabular}
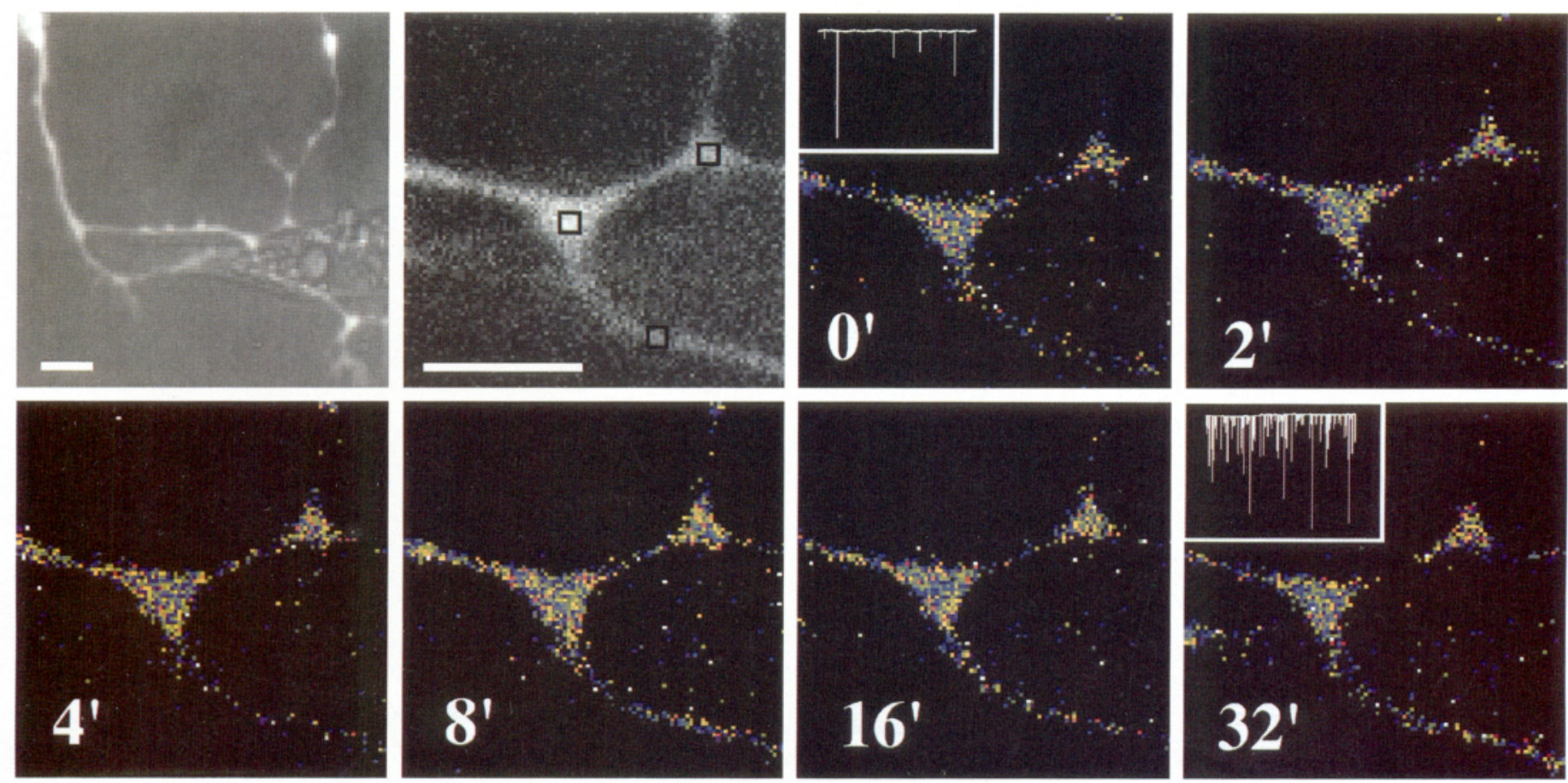

Figure 4. Fura-2 ratio imaging of $\left[\mathrm{Ca}^{2+}\right]_{\mathrm{i}}$ in the presynaptic neurons treated with BDNF and CNTF. The neuron was loaded with Fura- 2 through a whole-cell recording pipette at the soma. $A$, A neuron innervating a muscle cell was treated with $100 \mathrm{ng} / \mathrm{ml} \mathrm{BDNF}$ at time 0 (numbers in minutes), resulting in an increase in $\left[\mathrm{Ca}^{2+}\right]_{\mathrm{i}}$. The first black and white images represent fluorescence observed at $380 \mathrm{~nm}$ at low and high resolution, respectively, indicating the outline of presynaptic neurite surrounding a spherical postsynaptic myocyte. Squares mark the sites for which quantitative measurements of fluorescence intensity have been made (see Fig. 5). Color images depict $\left[\mathrm{Ca}^{2+}\right]_{\mathrm{i}}$ in the presynaptic neurite at various times after the BDNF treatment, shown in pseudo-colors with the corresponding $\mathrm{Ca}^{2+}$ concentration indicated by the color bar. Insets shown at 0 and 32 min are recordings of SSCs before and $32 \mathrm{~min}$ after BDNF administration. Bar, $10 \mu \mathrm{m}$. B, Same as in $A$, except that CNTF was applied instead of BDNF. In the first black and white micrograph, the fluorescence image at $380 \mathrm{~nm}$ was superimposed by a low-level bright-light image of the same field to reveal the geometry of the presynaptic neurite on an extended postsynaptic myocyte. Note the absence of any change in $\left[\mathrm{Ca}^{2+}\right]_{\mathrm{i}}$, whereas marked increase in SSCs was observed at 32 min after the CNTF treatment. 


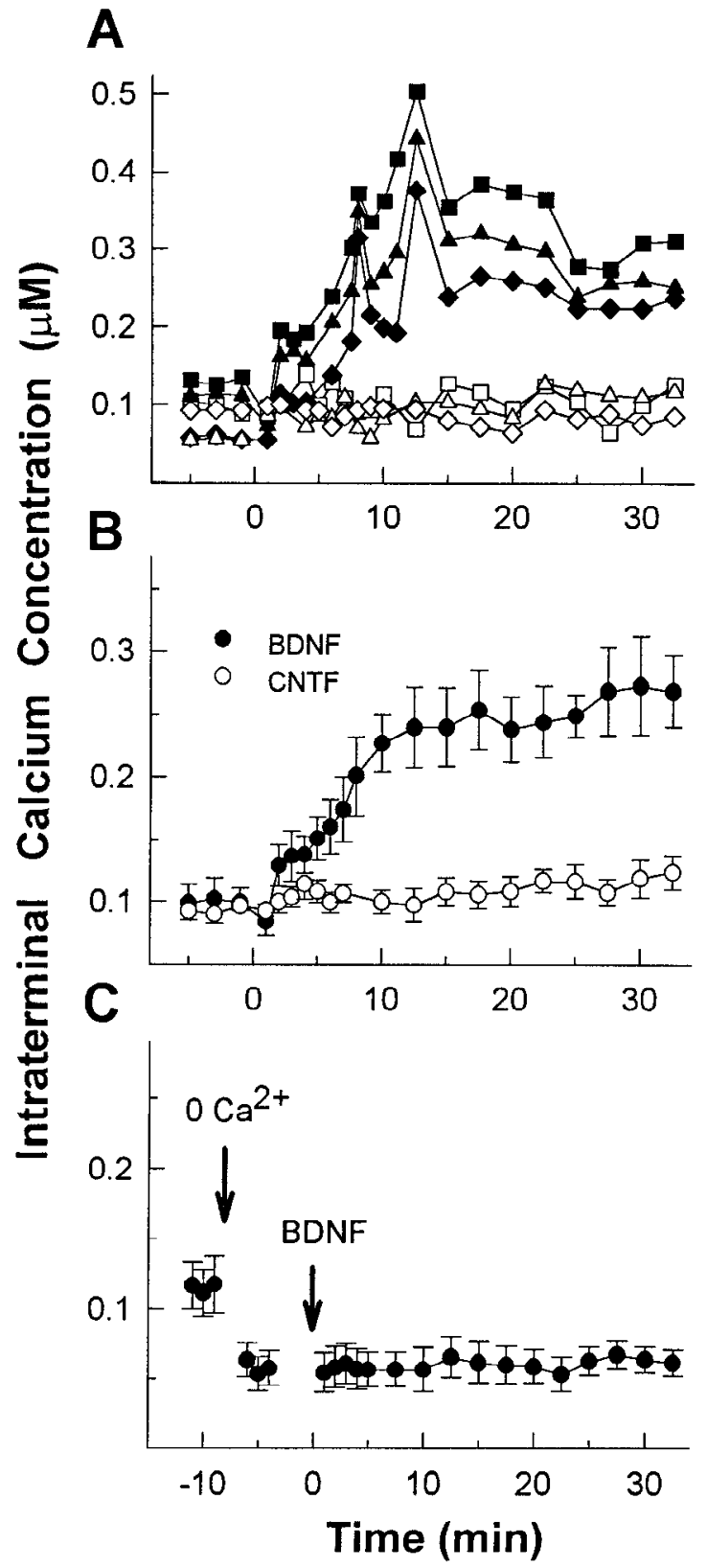

Figure 5. Changes in presynaptic $\left[\mathrm{Ca}^{2+}\right]$, induced by BDNF or CNTF treatment. $A,\left[\mathrm{Ca}^{2+}\right]_{\mathrm{i}}$ was measured with $2 \mathrm{~min}$ intervals at different locations of the presynaptic terminal shown in Figure 4 before and after the onset of BDNF or CNTF application (at time 0 ). The measurement boxes were $5 \times 5$ pixels, and their locations are indicated in Figure 4. The measurements made from the boxes in Figure 4 are represented from top to bottom in the same sequence by squares, triangles, and diamonds, respectively. Filled and open symbols represent synapses treated with $\mathrm{BDNF}$ and CNTF, respectively. $B$, Average $\left[\mathrm{Ca}^{2+}\right]_{1}$ changes over time for data collected from five synapses, each treated with BDNF and CNTF. The data points represent mean \pm SEM. $C$, The $\left[\mathrm{Ca}^{2+}\right]_{i}$ level was reduced by substitution of the external medium with $\mathrm{Ca}^{21}$-free solution (supplemented with EGTA and BSA; see Materials and Methods). Subsequent treatment of the culturc did not induce any clcvation of $\left[\mathrm{Ca}^{2+}\right]_{\mathrm{i}}$. The same protocol as that described above was used to measure presynaptic $\left[\mathrm{Ca}^{2+}\right]_{\mathrm{i}}$. Data points represent mean $\pm \operatorname{SEM}(n=5$ synapses).

exclude artifacts introduced by the loading procedure, only those synapses that showed no change in the SSC frequency after presynaptic Fura-2 loading were used for $\mathrm{Ca}^{2+}$ imaging. Figure $4 A$ shows an example of data from a Fura-2-loaded neuron before and at different times after BDNF treatment, using the standard ratio imaging method (Tsien and Poenie, 1986). An elevated $\left[\mathrm{Ca}^{2+}\right]_{i}$ in the presynaptic terminal of the Fura-2-loaded neuron was observed within a few minutes after BDNF addition, and the concentration remained at a high level in the presence of the factor for at least $30 \mathrm{~min}$. An example of quantitative measurements of $\left[\mathrm{Ca}^{2+}\right]_{\mathrm{i}}$ at several different presynaptic sites of the same neuron is shown in Figure $5 A$. Recording of SSCs from this particular synapse as well as two other synapses before and $30 \mathrm{~min}$ after the BDNF treatment confirmed the potentiation effect. In total, five synapses were examined for the BDNF effect on the presynaptic $\left[\mathrm{Ca}^{2+}\right]_{i}$, and the results are summarized in Figure $5 B$. Similar measurements of presynaptic $\left[\mathrm{Ca}^{2+}\right]_{i}$ were also performed for synapses treated with CNTF. As shown in Figures $4 B$ and 5 , no change in $\left[\mathrm{Ca}^{2+}\right]_{i}$ was observed after CNTF treatment, although recording of the same synapses confirmed that the SSC frequency at these synapses was increased by CNTF to the same level as typically observed in the absence of Fura-2 loading. Finally, we examined the dependence of BDNF-induced changes in $\left[\mathrm{Ca}^{2+}\right]_{i}$ on the presence of external $\mathrm{Ca}^{2+}$ by replacing culture medium with a $\mathrm{Ca}^{2+}$-free saline (see Materials and Methods). As shown in Figure $5 C$, depletion of external $\mathrm{Ca}^{2+}$ reduced the basal level of $\left[\mathrm{Ca}^{2+}\right]_{\mathrm{i}}$, and subsequent addition of BDNF produced no further change in $\left[\mathrm{Ca}^{2+}\right]_{i}$. Thus, the increased $\left[\mathrm{Ca}^{2+}\right]_{i}$ seemed to be the result of an elcvated influx of $\mathrm{Ca}^{2+}$.

\section{Dependence of synaptic potentiation on $\mathrm{Ca}^{2+}$}

In a series of experiments, we replaced the culture medium with $\mathrm{Ca}^{2+}$-free saline (see Materials and Methods) and measured the effect of BDNF and CNTF on spontaneous transmitter secretion. Depletion of external $\mathrm{Ca}^{2+}\left(\left[\mathrm{Ca}^{2+}\right]_{0}\right)$ caused a slight decrease in the basal SSC frequency. Further addition of BDNF in the absence of external $\mathrm{Ca}^{2+}$ was ineffective in elevating the SSC frequency. In contrast, administration of CNTF still led to a significant increase in the SSC frequency (Fig. 6). Cultures were also preincubated with BAPTA-AM $(20 \mu \mathrm{M})$ for $30 \mathrm{~min}$, which resulted in a drop in $\left[\mathrm{Ca}^{2+}\right]_{\mathrm{i}}$ to a level of $\sim 70 \%$ of its normal value, as shown by Fura-2 imaging (Girod et al., 1995). No clevated spontaneous release was observed after addition of either BDNF or CNTF (Fig. 6). Thus, both factors potentiated the exocytosis of a population of vesicles, which requires a basal level of cytosolic $\mathrm{Ca}^{2+}$ for the exocytic process.

\section{Different effects on short-term synaptic plasticity}

The difference in synaptic potentiation by BDNF and CNTF was studied further by examining the effects of these factors on shortterm plasticity of transmitter release upon repetitive activation of the synapse. First, we measured paired-pulse facilitation (PPF), the increase in the amplitude of the postsynaptic response when the synapse is activated by two successive presynaptic action potentials. This facilitation is known to reflect an enhanced transmitter release resulting from the residual $\mathrm{Ca}^{2+}$ in the presynaptic terminal (Zucker, 1989). At control neuromuscular synapses in 1-d-old Xenopus cultures, a slight PPF can be seen when the second pulse is applied $25 \mathrm{msec}$ after the first one (Fig. 7). After exposure of the culture to BDNF $(100 \mathrm{ng} / \mathrm{ml})$ for $30 \mathrm{~min}$, the amplitude of the ESC was potentiated, but this potentiation was accompanied by a disappearance of the PPF at $25 \mathrm{msec}$. Potentiation of the ESC amplitude by CNTF $(100 \mathrm{ng} / \mathrm{ml})$, on the other hand, had no effect on the PPF at these synapses. Thus, the potentiation effect of BDNF occludes PPF, whereas that of CNTF does not. 

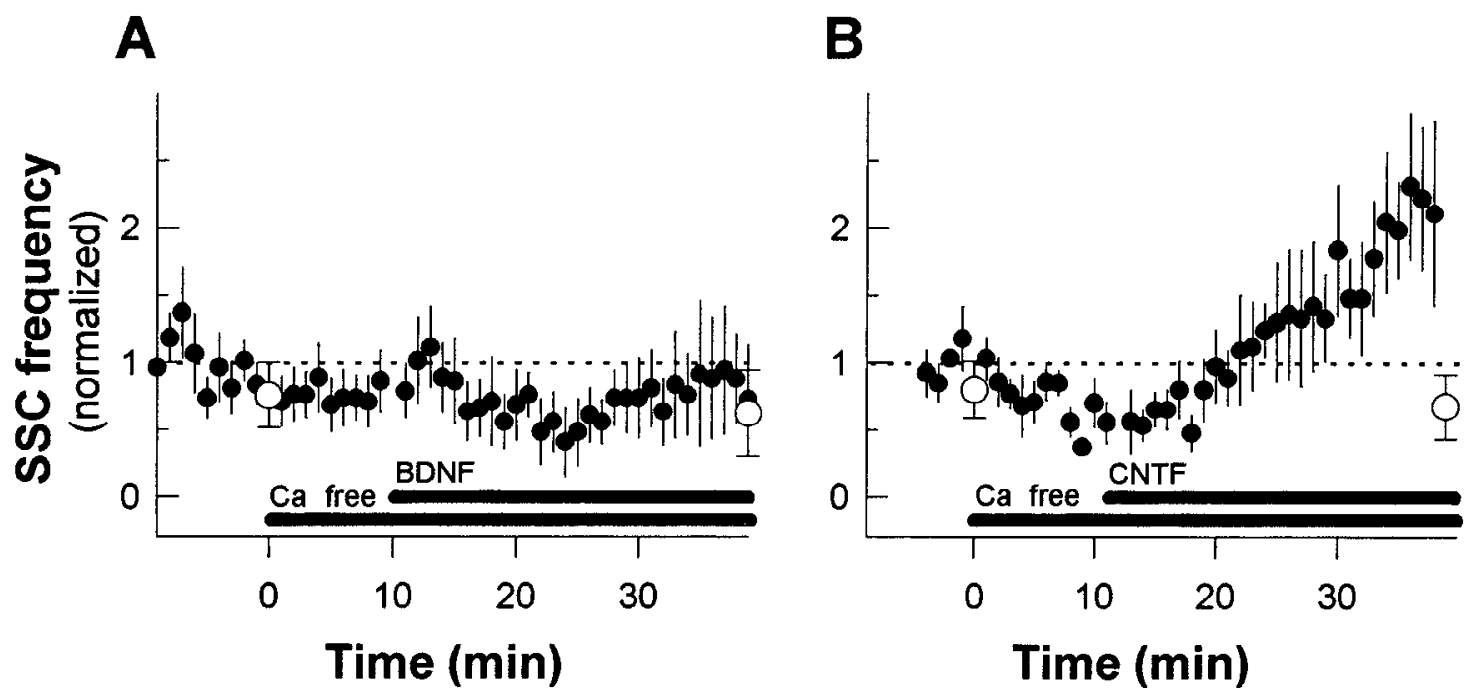

Figure 6. Dependence of BDNF and CNTF effects on $\mathrm{Ca}^{2+} . A$, The frequency of SSCs was monitored before and after the culture medium was substituted with $\mathrm{Ca}^{2+}$-free saline at the time marked by the lower bar. BDNF $(100 \mathrm{ng} / \mathrm{ml})$ was added to the $\mathrm{Ca}^{2+}$-free saline at time marked by the upper bar. The SSC frequency values recorded from each synapse were normalized against the average value of the same synapse before medium change. Data points represent mean $\pm \operatorname{SEM}(n=5$ synapses). $B$, The same as $A$ except that $\mathrm{CNTF}(100 \mathrm{ng} / \mathrm{ml})$ was added instead of BDNF $(n=6)$. In separate cultures, the cells were incubated with BAPTA-AM for $30 \mathrm{~min}$ before and throughout the experiment. For clarity, only results before and 30 min after application of either BDNF $(A)$ or CNTF $(B)$ were shown (open circles). Note that no potentiation of SSC frequency was observed after treatment with either factor.

Tetanic stimulation of presynaptic neurons of many synapses results in a gradual reduction in the average amplitude of evoked responses, a form of synaptic depression that can be attributed to the depletion of synaptic vesicles (Zucker, 1989). We examined the rate of tetanus-induced synaptic depression before and after treatment with either BDNF or CNTF. As shown in Figure 8, tetanic stimulation at a frequency of $5 \mathrm{~Hz}$ before the treatment of these factors resulted in a $50 \%$ reduction in the mean ESC amplitude within $30 \mathrm{sec}$, in agreement with that reported for tetanus-induced depression at these developing Xenopus synapses (Alder et al., 1995). After treatment with BDNF, the $30 \mathrm{sec}$ tetanus induced a similar extent of reduction in the ESC amplitude as compared with that observed during the pretreatment period. After treatment with CNTF, however, there was no obvious depression induced by the same $30 \mathrm{sec}$ tetanus that had produced a marked depression in untreated or BDNF-treated synapses.

\section{Synergistic actions of BDNF and CNTF}

The above studies suggested that different intracellular targets in the transmitter secretion machinery are affected by BDNF and CNTF. We explored this possibility further by examining whether the effects of these two factors are mutually exclusive by simultaneous application of both factors at different dose levels. We first determined the dose-response of each factor in potentiating the SSC frequency when applied alone. Either BDNF or CNTF was added to the culture at different concentrations, and the change in the SSC frequency was measured after $30 \mathrm{~min}$, when the effect had reached a plateau level (Lohof et al., 1993; Stoop and Poo, 1995). As shown in Figure 9, we found that the extent of potentiation of the SSC frequency was dose-dependent, and the effect apparently saturated at a level of $\sim 100 \mathrm{ng} / \mathrm{ml}$ for either BDNF or CNTF. When CNTF $(100 \mathrm{ng} / \mathrm{ml})$ was added to synapses that had been treated previously with a saturating dose of BDNF $(100 \mathrm{ng} / \mathrm{ml})$, a further increase in SSC frequency was observed. The same additive effect was observed when the order of treatment of the factors was reversed. Thus, a saturating action of one factor did not occlude further action of the other. The cooperative action of these factors in potentiating spontaneous transmitter secretion was revealed further by experiments using lower doses of BDNF and CNTF. As shown in Figure 9, treatment of the synapse with a single factor at either 1 or $10 \mathrm{ng} / \mathrm{ml}$ produced insignificant or small effects, respectively; however, combined treatments of both factors at these concentrations markedly potentiated the spontaneous transmitter secretion.

\section{DISCUSSION}

\section{Similar synaptic potentiation by BDNF and CNTF}

In the present study, we have compared the effects of two neurotrophic factors, BDNF and CNTF, on the physiological functions of developing neuromuscular synapses under various conditions. Although these two factors bind to distinctly different cell surface receptors and activate different intracellular signaling pathways (Heumann, 1994), the physiological effects of the two factors are quite similar: both caused increases in the frequency of SSCs and in the amplitude of action-potential ESCs. The SSCs found at these developing synapses are similar to miniature endplate currents at mature neuromuscular junctions and are independent of action potentials in these neurons (Xie and Poo, 1986). Flevation of SSC frequency was not attributable to spontaneous action potentials induced by the factor, because ESCs are usually of much large amplitudes than SSCs, and the amplitude distribution of SSCs after the potentiation by the factor did not exhibit any increase in the population of larger amplitudes. To determine whether BDNF and CNTF produce any postsynaptic changes in the response of the myocyte to the released transmitter, we have analyzed the amplitude distribution and the rise and decay times of the SSCs. The absence of any detectable changes in any of these parameters argues that within the duration of these experiments, the potentiation effects secm to be caused primarily by an clevated level of presynaptic $\mathrm{ACh}$ release without any changes in the postsynaptic ACh sensitivity.

Acute synaptic modulation by neurotrophins has been observed 
A
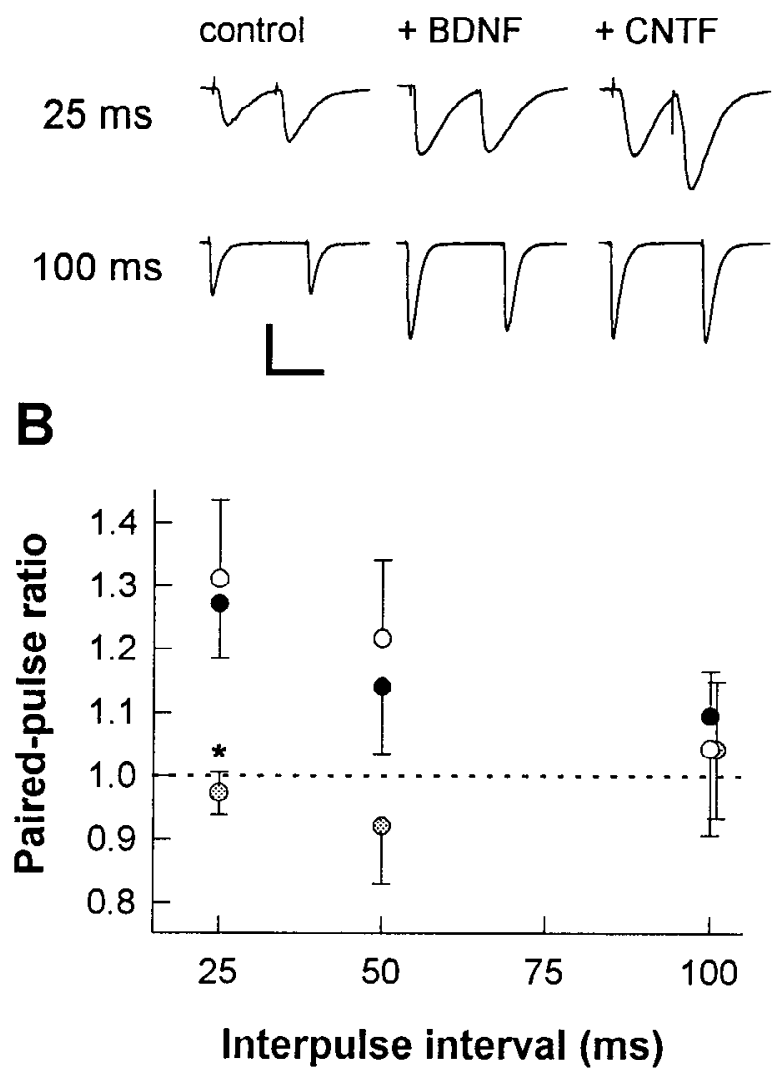

Figure 7. Differential effects of BDNF and CNTF on PPF facilitation. $A$, Samples of computer-averaged ESCs induced by a pair of pulses at an interval of $25 \mathrm{msec}$ or $100 \mathrm{msec}$ are shown for a control synapse and for synapses $30 \mathrm{~min}$ after treatment with CNTF or BDNF (at $100 \mathrm{ng} / \mathrm{ml}$ ). $B$, The ratio of the ESC amplitude induced by the second stimulus to that of the first paired-pulse ratio (PPR) for different interpulse intervals $(25,50$, 75 , and $100 \mathrm{msec}$ ) and different treatments: control (filled circles), CNTF (open circles), and BDNF (gray circles). For an interpulse interval of 25 msec, the PPR for synapse not treated with any factor (filled circle) and CNTF-treated synapses $(100 \mathrm{ng} / \mathrm{ml}, 30 \mathrm{~min}$ incubation; open circle) was significantly higher than that of BDNF-treated synapses $(100 \mathrm{ng} / \mathrm{ml}, 30$ min incubation; gray circle).

recently at a number of central synapses. Synaptic transmission is potentiated by neurotrophins in rat hippocampal slices (Berzaghi et al., 1995; Kang and Schuman, 1995a). At these hippocampal synapses, the effects of neurotrophins did not interfere with tetanus-induced long-term potentiation and seemed to be presynaptic in origin. In cultures of rat hippocampal neurons, BDNF elevates excitatory synaptic activity by potentiating glutamatergic synaptic transmission (Girod et al., 1994; Levine et al., 1995). In cultures of rat cortical neurons, however, NT-3 inhibited activities of GABAergic synapses with no apparent effect on excitatory synaptic transmission (Kim et al., 1994).

\section{The role of $\mathrm{Ca}^{2+}$ in BDNF and CNTF effects}

It is well known that the frequency of SSCs is affected directly by changes in intraterminal $\mathrm{Ca}^{2+}$ levels (Miledi, 1973). Using Fura-2 fluorescence imaging, Berninger et al. (1993) observed a transient increase in $\left[\mathrm{Ca}^{2+}\right]_{i}$ within 1 min aftcr application of BDNF to isolated hippocampal cells in culture. After BDNF administration, we found a gradual increase in $\left[\mathrm{Ca}^{2+}\right]_{\mathrm{i}}$ from $100 \mathrm{~nm}$ to up to 350 nM during a period of $10-15 \mathrm{~min}$. In all three cases for which SSCs
A
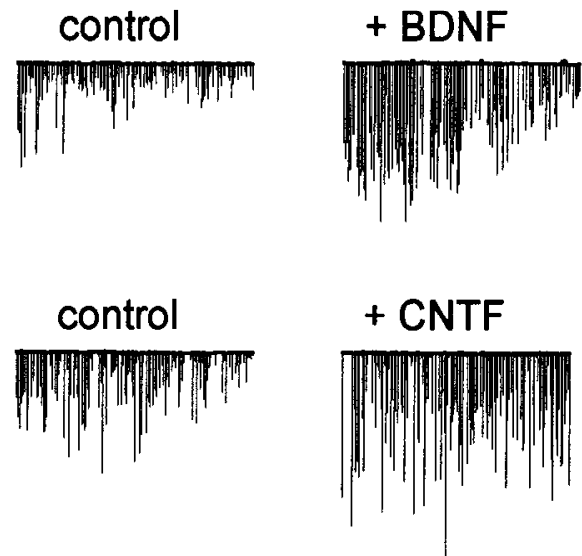

B

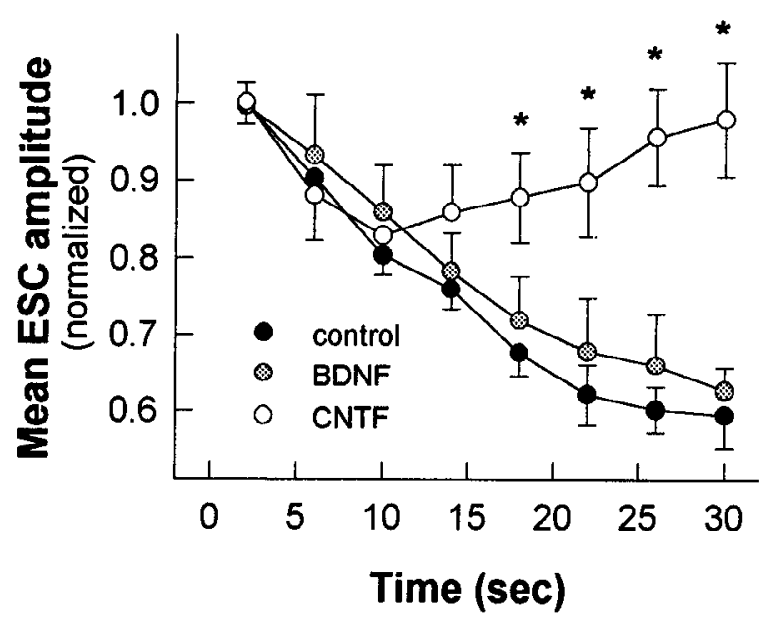

Figure 8. The effects of BDNF and CNTF on synaptic depression during tetanic stimulation. $A$, Examples of membrane currents recorded from postsynaptic myocyte during a train of tetanic stimulation at $5 \mathrm{~Hz}$ before (left) and 30 min after (right) treatment with CNTF or BDNF (both at 100 $\mathrm{ng} / \mathrm{ml}) . B$, Changes in the mean ESC amplitude over time during tetanic stimulation at $5 \mathrm{~Hz}$ at control synapses (before treatments with the factors; filled circles; $n=6)$, BDNF-treated synapses $(100 \mathrm{ng} / \mathrm{ml}, 30 \mathrm{~min}$ incubation; gray circles; $n=6)$, and CNTF-treated synapses $(100 \mathrm{ng} / \mathrm{ml}, 30 \mathrm{~min}$ incubation; open circles; $n=6$ ). Mean ESC amplitudes during $4 \mathrm{sec}$ intervals were normalized to the mean ESC amplitude during the first 4 sec after the onset of tetanus. The normalized amplitudes at $18,22,26$, and $30 \mathrm{sec}$ (marked by *) are significantly different from values observed at control and BDNF-treated values $(p<0.05, t$ test $)$.

were monitored before and after fluorescence measurements, an increase in SSC frequency was observed. The elevations of $\left[\mathrm{Ca}^{2+}\right]_{i}$ after administration of BDNF (Fig. 6A) exhibited a time course similar to that of the increase in SSC frequency reported carlicr (Lohof et al., 1993; Stoop and Poo, 1995). In contrast, we failed to observe any change in $\left[\mathrm{Ca}^{2+}\right]_{\mathrm{i}}$ in all five cases for which the SSC frequency was elevated by CNTF. Thus, an increase in $\left[\mathrm{Ca}^{2+}\right]_{i}$ at the nerve terminal induced by BDNF may account for the increase in SSC frequency, whereas a change in $\left[\mathrm{Ca}^{2+}\right]_{i}$ does not seem to be involved in the CNTF effect.

The mechanism by which BDNF causes an elevation in $\left[\mathrm{Ca}^{2+}\right]_{\mathrm{i}}$ may involve the action of phospholipase C (PLC). Both BDNF and NT-3 stimulate phosphorylation of PLC and subsequent phosphatidyl-inositol-hydrolysis in cultured rat cortical neurons (Widmer et al., 1993). BDNF also increases the concentration of 


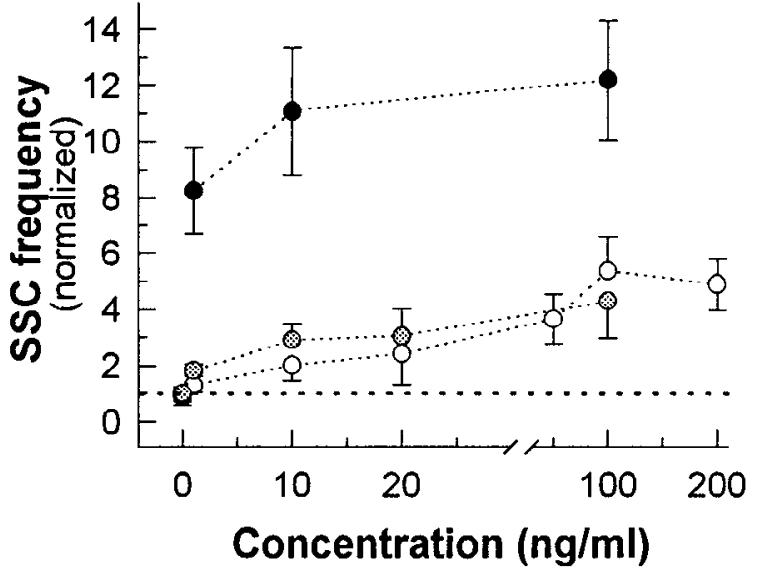

Figure 9. Synergistic effects by CNTF and BDNF in potentiation of spontaneous $\mathrm{ACh}$ secretion. The mean SSC frequency observed 30 min after application of different concentrations of CNTF (open circles) or BDNF (gray circles) or both (solid circles) to the culture. The frequency values were normalized for each synapse by the mean value observed at the same synapse before addition of the factor. The data points represent mean \pm SEM $(n=8-12)$. The differences between values at $100 \mathrm{ng} / \mathrm{ml}$ CNTF and at 0,2 , or $10 \mathrm{ng} / \mathrm{ml} \mathrm{CNTF}$ are statistically significant. The differences between values at $100 \mathrm{ng} / \mathrm{ml} \mathrm{BDNF}$ and at 0 or $2 \mathrm{ng} / \mathrm{ml} \mathrm{BDNF}$ are also statistically significant. All values observed for combined BDNF and CNTF treatments are significantly different from values for BDNF or CNTF treatment alone at the corresponding concentration $(p<0.05$, $t$ test).

inositol triphosphate $\left(\mathrm{IP}_{3}\right)$ in rat hippocampal synaptosomes (Knipper et al., 1993). Because the BDNF-induced rise in $\left[\mathrm{Ca}^{2+}\right]_{i}$ was abolished by removal of external $\mathrm{Ca}^{2+}$ (Fig. $5 \mathrm{C}$ ), the rise in $\left[\mathrm{Ca}^{2+}\right]_{\mathrm{i}}$ may be attributed directly to the BDNF-induced elevation of $\mathrm{Ca}^{2+}$ influx. Alternatively, external $\mathrm{Ca}^{2+}$ may be required for signal transduction by $\mathrm{BDNF}$, and the elevation of $\mathrm{IP}_{3}$ triggers $\mathrm{Ca}^{2+}$ release from internal stores.

In the hippocampus, L-type $\mathrm{Ca}^{2+}$ channels may be involved in the synaptic potentiation by BDNF, because administration of nifedipine, a blocker of these channels, prevents potentiation by BDNF (Kang and Schuman, 1995b). In addition to potential direct modulation of $\mathrm{Ca}^{2+}$ channels in these Xenopus neurons (O’Dowd et al., 1988; Ribera and Spitzer, 1990; Barish, 1991a,b), neurotrophins may affect $\mathrm{Ca}^{2+}$ entry during the action potential by altering voltage-dependent $\mathrm{K}^{+}$conductances. Although changes in the expression of voltage-dependent ion channels can be induced by long-term application of neurotrophic factors (Lesser and Lo, 1995; Nick et al., 1995), whether ion channel modulation is involved in the acute actions of neurotrophic factors reported here remains to be examined.

\section{Effects of BDNF and CNTF on short-term synaptic plasticity}

The differences in the mechanism by which BDNF and CNTF potentiate the transmitter release were revealed further by the differential effects of these factors on activity-dependent plasticity in transmitter release. In PPF, the facilitated transmitter secretion triggered by the second presynaptic stimulus is attributed to the residual $\mathrm{Ca}^{2+}$ resulting from the first stimulus (Kamiya and Zucker, 1994). We found that potentiation by BDNF reduced the magnitude of the PPF that is normally seen at these synapses, whereas CNTF had no effect. Elevated $\left[\mathrm{Ca}^{2+}\right]_{\mathrm{i}}$ resulting from increased external $\mathrm{Ca}^{2+}$ concentration is known to reduce PPF (Rahamimoff, 1968). The BDNF effect in reducing PPF is thus consistent with the elevated $\left[\mathrm{Ca}^{2+}\right]_{\mathrm{i}}$ induced by this factor.
Under repetitive stimulation, developing neuromuscular junctions exhibit marked reduction of ESC amplitudes over time, presumably as a result of depletion of synaptic vesicles. This synaptic depression essentially was abolished by treatment with CNTF, suggesting that CNTF may help to mobilize vesicle supply at these synapses. Because the amplitude of the ESCs observed at a low stimulus frequency was increased by CNTF, the immediate availability of vesicle and/or probability of vesicle exocytosis was also increased by CNTF. Finally, we noted that the effects of CNTF persisted for a longer duration than those of BDNF after the factors were removed from the culture medium. As shown in a previous study (Stoop and Poo, 1995), potentiation of spontaneous $\mathrm{ACh}$ release by $\mathrm{CNTF}$, in contrast to that by BDNF, requires signaling with the cell body, because $\mathrm{CNTF}$ was ineffective in potentiating synapses that were "cut loose" from the cell body. Such a long-range somatic signaling induced by CNTF may involve an increase in vesicle supply that results in a more persistent increase of transmitter release and reduced synaptic depression during high-frequency stimulation.

\section{Synergistic actions of BDNF and CNTF}

Dose-response studies of the potentiation effects of BDNF and CNTF on spontaneous ACh secretion showed that near maximal potentiation by one factor (obtained at a concentration of 100 $\mathrm{ng} / \mathrm{ml}$ after $30 \mathrm{~min}$ treatment) did not occlude subsequent potentiation by the other factor. Thus, it seems that these two factors act on different sites of the transmitter secretion machinery. At low concentrations of both BDNF and CNTF, simultaneous exposure to both factors led to a marked potentiation of the spontaneous release that cannot be explained purely by the additive effects of the two factors. Long-term synergistic actions of BDNF and CNTF have been reported for the induction of choline acetyltransferase (Wong et al., 1993, 1995; Xu et al., 1995) and for improving the performance of Wobbler mice (Klinkosz et al., 1995). Our results show that acute synaptic effects of BDNF and CNTF also can be synergistic. At the presynaptic nerve terminal, down-stream effectors activated by BDNF and CNTF may act on two different but sequential steps in the secretion machinery, leading to a synergistic effect on transmitter secretion. Whether such synergistic action of neurotrophic factors plays a role in regulating the development and functioning of neuromuscular synapses in the nervous system remains to be investigated.

\section{REFERENCES}

Alder J, Kanki H, Valtorta F, Greengard P, Poo M-m (1995) Overexpression of synaptophysin enhances neurotransmitter secretion at $X \mathrm{c}$ nopus neuromuscular synapses. J Neurosci 15:511-519.

Arakawa Y, Sendtner M, Thoenen H (1990) Survival effect of ciliary neurotrophic factor (CNTF) on chick embryonic motoneurons in culture: comparison with other neurotrophic factors and cytokines. J Neurosci 10:3507-3515

Barish ME (1991a) Voltage-gated calcium currents in cultured embryonic Xenopus spinal neurones. J Physiol (Lond) 444:523-543.

Barish ME (1991b) Increases in intracellular calcium ion concentration during depolarization of cultured embryonic Xenopus spinal neurones. J Physiol (Lond) 444:545-565.

Berninger B, Garcia DE, Inagaki N, Hahnel C, Lindholm D (1993) BDNF and NT-3 induce intracellular $\mathrm{Ca}^{2+}$ elevation in hippocampal neurons. NeuroReport 4:1303-1306.

Berzaghi MP, Gutiérrez R, Heinemann U, Lindholm D, Thoenen $H$ (1995) Neurotrophins induce acute transmitter-mediated changes in brain electrical activity. Soc Neurosci Abstr [Suppl] 21:226.3.

Connolly JL, Seeley PJ, Greene LA (1985) Regulation of growth cone morphology by nerve growth factor: a comparative study by scanning electron microscopy. J Neurosci Res 13:183-198. 
Connolly JL, Seeley PJ, Greene LA (1987) Rapid regulation of neurona growth cone shape and surface morphology by nerve growth factor Neurochem Res 12:861-868.

Conover JC, Erickson JT, Katz DM, Bianchi LM, Poueymirou WT, McClain J, Pan L, Helgren M, Ip NY, Boland R, Friedman B, Wiegand S, Vejsada R, Kato AC, DeChiara TM, Yancopoulos GD (1995) Neuronal deficits, not involving motoneurons, in mice lacking BDNF and/or NT4. Nature 375:235-238.

Evers J, Laser M, Sun Y, Xie ZP, Poo M-m (1989) Studies of nervemuscle interactions in Xenopus cell culture: analysis of early synaptic currents. J Neurosci 9:1523 1539.

Forger NG, Roberts SL, Wong V, Breedlove SM (1993) Ciliary neurotrophic factor maintains motoncurons and their target muscles in developing rats. J Neurosci 13:4720-4726.

Girod R, Cash S, Poo M-m (1994) Brain derived neurotrophic factor (BDNF) potentiates excitatory synaptic transmission in hippocampal neurons in culture Soc Neurosci Abstr 20:855.

Girod R, Popov S, Alder J, Zheng JQ, Lohof AM, Poo M-m (1995) Spontaneous quantal transmitter secretion from myocytes and fibroblasts: comparison with neuronal secretion. J Neurosci 15:2826-2838.

Greene LA, Kaplan DR (1995) Early events in neurotrophin signaling via Trk and p75 receptors. Curr Opin Neurobiol 5:579-587.

Grynkiewicz G, Poenie M, Tsien RY (1985) A new generation of $\mathrm{Ca}^{2+}$ indicators with greatly improved fluorescence properties. J Biol Chem 260:3440-3450.

Hamill OP, Sakmann B (1981) Multiple conductance states of single acetylcholine receptor channels in embryonic muscle cells. Nature 294:462-464.

Henderson CE, Camu W, Mettling C, Gouin A, Poulsen K, Karihaloo M, Rullamas J, Evans T, McMahon SB, Armanini MP, Berkemeier L, Phillips HS, Rosenthal A (1993) Neurotrophins promote motor neuron survival and are present in embryonic limb bud. Nature $363: 266-270$.

Heumann R (1994) Neurotrophin signalling. Curr Opin Neurobiol 4:668-679.

Kamiya H, Zucker RS (1994) Residual $\mathrm{Ca}^{2+}$ and short-term synaptic plasticity. Nature 371:603-606.

Kang H, Schuman EM (1995a) Long-lasting neurotrophin-induced enhancement of synaptic transmission in the adult hippocampus. Science 267:1658-1662.

Kang H, Schuman EM (1995b) Characterization of neurotrophininduced synaptic potentiation in area $\mathrm{CA} 1$ of the rat hippocampus. Soc Neurosci Abstr 21:599.

Kim HG, Wang T, Olafsson P, In B (1994) Neurotrophin 3 potentiates neuronal activity and inhibits gamma-aminobutyratergic synaptic transmission in cortical neurons. Proc Natl Acad Sci USA 91:12341-12345.

Klinkosz B, Misumoto H, Cedarbaum JM, Wong V, Lindsay RM (1995) The effects of prolonged co-administration of CNTF and BDNF in Wobbler mice. Soc Neurosci Abstr 21:1005.

Knipper M, Beck A, Rylett J, Breer H (1993) Neurotrophin induced second messenger responses in rat brain synaptosomes. NeuroReport 4:483-486.

Koliatsos VE, Clatterbuck RE, Winslow JW, Cayouette MH, Price DL (1993) Evidence that brain-derived neurotrophic factor is a trophic factor for motor neurons in vivo. Neuron 10:359-367.

Lesser SS, Lo DC (1995) Regulation of voltagc-gated ion channels by $\mathrm{NGF}$ and ciliary neurotrophic factor in SK-N-SH neuroblastoma cells. J Neurosci 15:253-261.

Levine ES, Dreyfus CF, Black IB, Plummer MR (1995) Brain-derived neurotrophic factor rapidly enhances synaptic transmission in hippocampal neurons via postsynaptic tyrosine kinase receptors. Proc Natl Acad Sci USA 92:8074-8077.
Liu X, Ernfors P, Wu H, Jaenisch R (1995) Sensory but not motor neuron deficits in mice lacking NT4 and BDNF. Naturc 375:238-241.

Lohof AM, Ip NY, Poo M-m (1993) Potentiation of developing neuromuscular synapses by the neurotrophins NT-3 and BDNF. Nature 363:350-353.

Masu Y, Wolf E, Holtmann B, Sendtner M, Brem G, Thoenen H (1993) Disruption of the CNTF gene results in motor neuron degeneration. Nature 365:27-32.

Miledi R (1973) Transmitter release induced by injection of calcium ions into nerve terminals. Proc R Soc Lond [Biol] 183:421-425.

Nick TA, McKay SE, Kaczmarek LK, Carew 'J (1995) Outward currents of Aplysia bag cell neurons decrease with development of afterdischarge and with BDNF treatment. Soc Neurosci Abstr 21:535.

Nieuwkoop PD, Faber J (1967) Normal table of Xenopus laevis (Daudin), 2nd Ed. Amsterdam: North Holland.

O'Dowd DK, Ribera AB, Spitzer NC (1988) Development of voltagedependent calcium, sodium, and potassium currents in Xenopus spinal neurons. J Neurosci 8:792-805.

Oppenheim RW, Prevette D, Yin QW, Collins F, MacDonald J (1991) Control of embryonic motoneuron survival in vivo by ciliary neurotrophic factor. Science 251:1616-1618.

Rahamimoff $\mathrm{R}$ (1968) A dual effect of calcium ions on neuromuscular facilitation. J Physiol (Lond) 195:471-480.

Ribera AB, Spitzer NC (1990) Differentiation of IKA in amphibian spi nal neurons. J Neurosci 10:1886-1891.

Sendtner M, Holtmann B, Kolbeck R, Thoenen H, Barde YA (1992) Brain-derived neurotrophic factor prevents the death of motoneurons in newborn rats after nerve section. Nature 360:757-759.

Spitzer NC, Lamborghini JC (1976) The development of the action potential mechanism of amphibian neurons isolated in culture. Proc Natl Acad Sci USA 73:1641-1645.

Stoop R, Poo M-m (1995) Potentiation of transmitter release by ciliary neurotrophic factor requires somatic signaling. Science 267:695-699.

Tabti N, Poo M-m (1991) Culturing spinal neurons and muscle cells from Xenopus embryos. In: Culturing nerve cells (Banker G, Gosslin K, eds), pp 137-154. Cambridge: MIT.

Tsien RY, Poenie M (1986) Fluorescence ratio imaging: a new window into intracellular ionic signaling. Trends Biochem Sci 11:450-455.

Widmer HR, Kaplan DR, Rabin SJ, Beck KD, Hefti F, Knusel B (1993) Rapid phosphorylation of phospholipase $\mathrm{C}$ gamma 1 by brain-derived neurotrophic factor and neurotrophin-3 in cultures of embryonic rat cortical neurons. J Neurochem 60:2111-2123.

Wong V, Arriaga R, Ip NY, Lindsay RM (1993) The neurotrophins BDNF, NT-3 and NT-4/5, but not NGF, up-regulate the cholinergic phenotype of developing motor neurons. Eur J Neurosci 5:466-474.

Wong V, Song Y, Arriaga R, Lindsay RM (1995) CNTF potentiates the effects of BDNF, GDNF, or HGF in cultured motor neurons. Soc Neurosci Abstr 21:1535.

Xie Z, Poo M-m (1986) Initial events in the formation of neuromuscular synapse: rapid induction of acetylcholine release from embryonic neuron. Proc Natl Acad Sci USA 83:7069-7073.

Xu RY, Kahn S, Lile J (1995) Comparison of the effects of CNTF, BDNF and GDNF on cultured motor neurons. Soc Neurosci Abstr 21:1535.

Yan Q, Elliott J, Snider WD (1992) Brain-derived neurotrophic factor rescues spinal motor neurons from axotomy-induced cell death. Nature 360:753-755.

Zheng JQ, Felder M, Connor JA, Poo M-m (1994) Turning of nerve growth cones induced by neurotransmitters. Nature 368:140-144.

Zucker RS (1989) Short-term synaptic plasticity. Annu Rev Neurosci $12: 13-31$ 